\title{
An Experimental Study of Laminar Flow for Graphene Nanofluid in Double Micro Heat Exchanger
}

\author{
Mahmoud Abdallah \\ Mechanical Engineering Dept., \\ Faculty of Energy Engineering \\ Aswan University \\ Aswan, Egypt \\ M. Shaban Eissa \\ Mechanical Engineering Dept., \\ Faculty of Energy Engineering \\ Aswan University \\ Aswan, Egypt
}

\author{
Mohamed Salem \\ Mechanical Engineering Dept., \\ Faculty of Energy Engineering \\ Aswan University \\ Aswan, Egypt \\ W. A. Aissa* \\ Mechanical Engineering Dept., \\ Faculty of Energy Engineering \\ Aswan University \\ Aswan, Egypt
}

\begin{abstract}
In this paper, an experimental study was conducted on double micro-heat exchanger device for laminar heat transfer of the Graphene Nano platelets. The heat transfer, pressure drop and pumping power of Graphene Nano fluid were measured. First, the Nano fluid was prepared and the stability of the Nano fluid was measured, then the thermal properties (viscosity, density, and thermal conductivity) were measured experimentally in the laboratory at different concentrations $(0.02,0.055$ and $0.06 \%$ wt.). In addition, the effect of weight fraction, inlet temperature and mass flow rate on logarithmic mean temperature difference and the overall heat transfer coefficient were evaluated in double micro-heat exchanger device. The final results showed that the overall heat transfer coefficient and effectiveness of double micro-heat exchanger device improved by raising the weight fraction of Graphene Nano platelets and the overall heat transfer coefficient improved to $51.1 \%$ at Reynolds number of 425 and weight concentration of $0.06 \%$ wt. The experimental results showed that pressure drop and pumping power were higher for $(0.06 \%$ wt. $)$ compared to $(0.02 \%$ wt. and $0.055 \%$ wt.).
\end{abstract}

Keywords - Nanofluid, Graphene, Double micro-heat exchanger.

\section{INTRODUCTION}

Transport of energy is playing vital role in different applications such as electrical energy, oil, gas and nuclear energy. Many of applications use traditional heat transfer fluids such as distilled Water, pumping oil, ethylene glycol (EG) and glycerol. Enhancing the thermal conductivity of fluids becomes needful for performance systems of energy [1,2]. References [3-7] stated that Nano fluids refer to the nanoparticle mixing with liquid to upgrade the thermo physical properties such as thermal conductivity resulting in good stability and enhancement of heat transfer coefficients and increment in the pressure drop and pumping power. A lot of papers investigate experiments conducted to upgrade the properties of thermo fluids by adding Nano scale particles to liquids. Experimental studies for heat transfer coefficient for Nano fluids across tubes as different types [8-10] showed that many types of Nano scale particles include oxides, diamond, metals and carbon Nano particles. Experiments have been done on $\mathrm{TiO} 2, \mathrm{CuO}, \mathrm{Al} 2 \mathrm{O} 3$, and $\mathrm{SiO} 2$ Nano fluids $[11,12]$ to investigate the effect of the weight fraction of nanoparticles on the thermal properties of fluids and heat transfer coefficients. It was noticed that the range of increment in the convective heat transfer coefficients under turbulent and laminar flow conditions varied from $26 \%$ to $35 \%$ $[13,14]$.

It was deduced that the effect of Nano fluid focusing on the heat transfer coefficient is important in the turbulent regime versus the laminar regime $[15,16]$.

Duangthongsuk. and Wongwises [17] and Khedkar et al. [18] prepared $\mathrm{TiO} 2(21 \mathrm{~nm})$ Nano fluid and used water as base fluid for various concentrations $(0.2-2 \% \mathrm{wt}$.) in horizontal double tubebased heat exchanger as counter flow in turbulent region and studied the convective heat transfer and pressure drop of Nano fluid.

Newly, various researches were conducted to study improving the performance of heat transfer by enhancing the thermal conductivity of base fluid. Carbonic materials have low density and high thermal conductivity compared with other metals and metal oxides. Number of researches studied carbon Nano-based nanostructures, including carbon nanotubes, carbon Nano fibers, carbon black structures, graphene oxide (GO), graphene Nano sheets and graphite flakes [19-24]

Novoselov et al. [25] are the first researchers who explored graphene. Graphene is a 2D carbon material arranged as monolayer material; its physical properties are high thermal conductivities and low densities. Balandin et al. [26] and Baby and Ramaprabhu [27] indicated that thermal conductivity of graphene can be as high as $3 \mathrm{~kW} / \mathrm{mK}$ in axial and $5.2 \mathrm{~kW} / \mathrm{mK}$ in-plane.

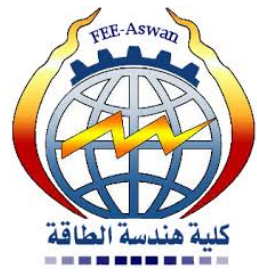


Ebrahimnia-Bajestan et al. [28] studied the convective heat transfer of Nano fluids. No complete papers in this area explain the various effective parameters. There were some researches which show that the improvement in heat transfer coefficient due to Nano fluids are associated with a number of undesirable effects and calculated the pressure drop and pumping power required to achieve the best of Nano fluid to be used in the applications of heat transfer.

In this study, the laminar counter flow of graphene/distilled water Nano fluid in Double Micro Heat Exchanger (DMHE) is investigated experimentally. Nano fluids are prepared from graphene and water at different weight concentrations $(0.02$, 0.055 and $0.06 \%$ wt.) The thermo physical properties were measured at different temperatures and concentrations, and then used the micro heat exchanger to calculate the heat transfer characteristics of Nano fluids for Reynolds numbers varying from 125 to 425 . The influence of weight concentration on pressure drops, pumping power, and heat transfer coefficient under various Reynolds numbers are investigated. A flow chart is utilized to have a better understanding of the sequence of the current investigation is shown in Fig 1.

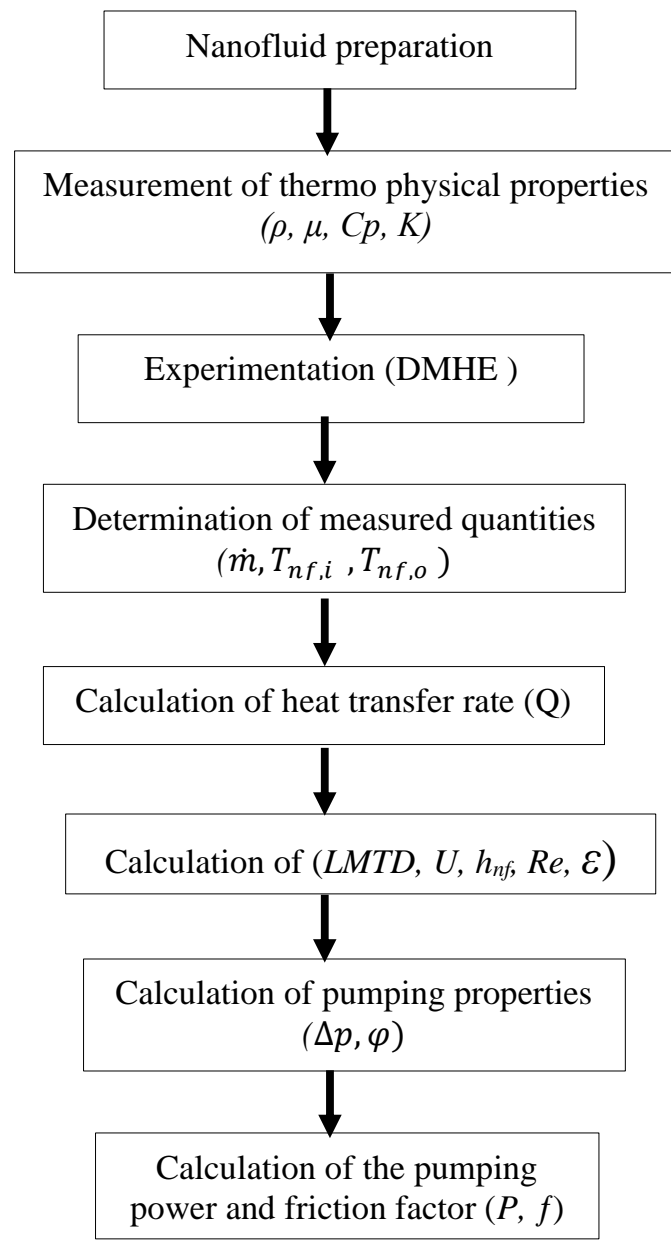

Fig. 1 Flow chart of the current study progress

\section{Abbreviations}

\section{DMHE Double Micro Heat Exchanger \\ GNP Graphene Nano platelet \\ SDBS Sodium Dodecyl Benzene Sulfonate}

\section{Nomenclatures}

A Heat transfer area $\left(\mathrm{m}^{2}\right)$

C Thermal capacity (-)

$C p \quad$ Specific heat capacity $(\mathrm{J} / \mathrm{kg} . \mathrm{K})$

$D_{i} \quad$ Inner diameter of inner tube for DMHE (m)

$d \quad$ Inner diameter of pipe (m)

$f \quad$ Darcy friction factor (-)

$h \quad$ Convective heat transfer coefficient $\left(\mathrm{W} / \mathrm{m}^{2} . \mathrm{K}\right)$

$K \quad$ Thermal conductivity (W/m.K)

$L \quad$ Length of pipe (m)

LMTD Logarithmic Mean Temperature Difference (K)

NTU Number of transfer units (-)

$\dot{m} \quad$ mass flow rate $(\mathrm{Kg} / \mathrm{s})$

$\mathrm{Nu} \quad$ Nusselt number (-)

$P \quad$ Pumping power $(\mathrm{W})$

$\Delta P \quad$ Pressure drop $(\mathrm{KPa})$

$Q \quad$ Heat transfer rate $(\mathrm{J} / \mathrm{s})$

Re Reynolds number (-)

$T \quad$ Temperature (K)

$t \quad$ Time (s)

$U \quad$ The overall heat transfer coefficient $\left(\mathrm{W} / \mathrm{m}^{2} . \mathrm{K}\right)$

$V \quad$ Nano fluid velocity $(\mathrm{m} / \mathrm{s})$

\section{Greek symbols}

$\mu \quad$ Absolute viscosity (m Pa.s)

$\varepsilon \quad$ Effectiveness of DMHE (-)

$\rho \quad$ Density $\left(\mathrm{kg} / \mathrm{m}^{3}\right)$

$\varphi \quad$ Volumetric flow rate $\left(\mathrm{m}^{3} / \mathrm{s}\right)$

$\varnothing \quad$ Weight fraction (-)

Subscripts

$F \quad$ Base fluid

In Inlet

nf Nano fluid

out Outlet

$p \quad$ Particle

w Water

2- Nano fluid preparation and measurements of stability

References [29-34] used two steps technique for preparation of Nano fluid because it is economic and wide range. Similarly, in this work, two steps technique was used. The specifications of the GNPs are listed in table 1 .

Nanoparticles (GNPs) were added to base fluid (distilled water) with the surfactant Sodium Dodecyl benzenesulfonate (SDBS) to reduce the aggregation due to London-van der Waals reaction according to the literature survey[34]. GNPs were mixed with water by using ultrasonic homogenize (VCX-500 Ultrasonic Processor 500 Watts, 60 amplitude) for one hour. Five weight concentrations $(0.02, \cdot .03,0.04,0.055$ and $0.06 \%$ wt.) were prepared and mixed with distilled water. If high concentrations of Nano fluids is used (>0.06\% wt.); the viscosity increases and it becomes difficult for the Nano fluids 
to pass through the micro heat exchanger. Low concentrations of Nano fluids $(<0.02 \%$ wt.) are utilized in previous studies [ $r \varepsilon]$, Fig .2 shows the stability of Nano fluid after 90 days, and additional techniques used to find out the stability of Nano fluid called Zeta potential which gave good result for stability of Nano fluid for $0.06 \%$ wt. in Fig .3.

Table 1. Properties of GNPs

\begin{tabular}{lc}
\hline \multicolumn{1}{c}{ Property } & Specification \\
\hline Appearance & Black granules \\
Carbon content & $>99.5 \% \mathrm{wt}$. \\
Surface area & $300 \mathrm{~m}^{2} / \mathrm{g}$ \\
Thickness & $5-10 \mathrm{~nm}$ \\
Width & $5 \mu \mathrm{m}$ \\
Bulk density & $0.03-.1 \mathrm{~g} / \mathrm{cc}$ \\
Thermal conductivity (parallel to surface) & $3000 \mathrm{~W} / \mathrm{mK}$ \\
Thermal conductivity (perpendicular to surface) & $6 \mathrm{~W} / \mathrm{m} \mathrm{K}$ \\
\hline
\end{tabular}

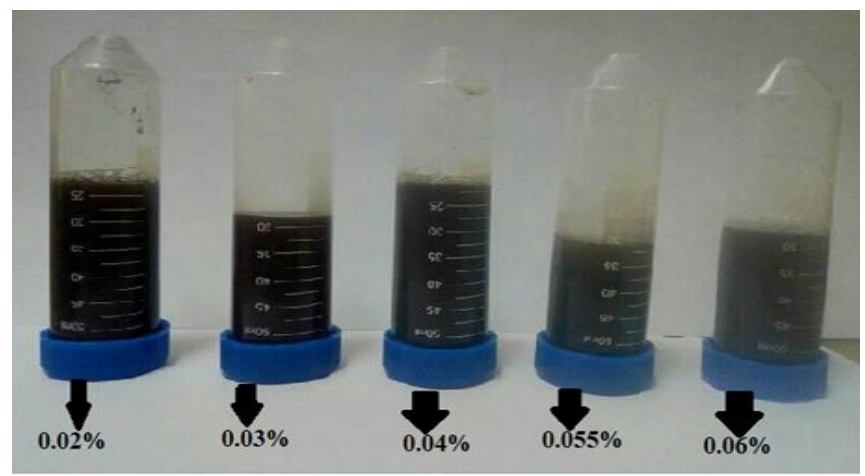

Fig. 2 Nano fluid after 90 days

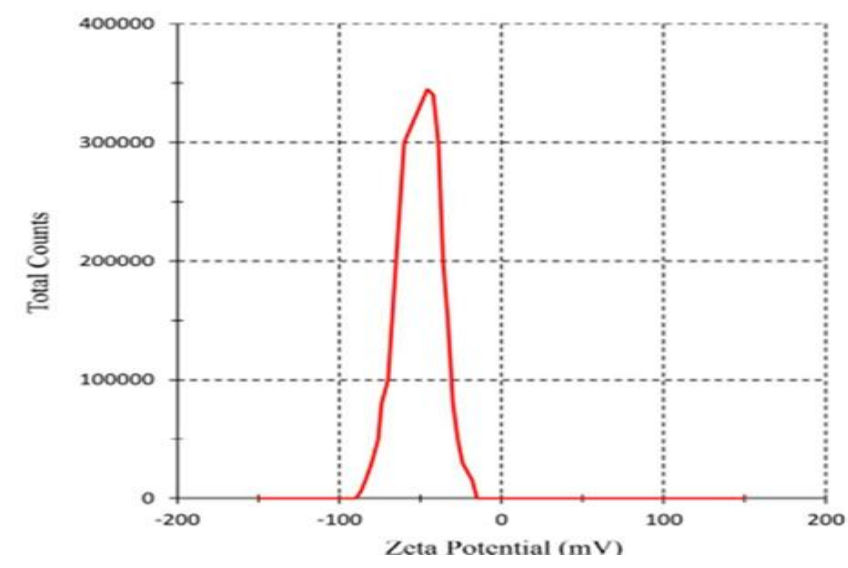

Fig. 3 Zeta potential distribution of (0.06\% wt.) GNPs at water

\section{3-Thermophysical properties of Nano fluids}

\subsection{Viscosity}

The graphene Nano fluids viscosity at different concentrations was measured using Ostwald U-Tube Viscometer [35].

Fig.4 shows the measured Nano fluid viscosity for various concentrations at different temperatures in the current study. The viscosity of Nano fluids increased exponentially as a function of nanoparticles concentration and the viscosity decreased with increasing the temperature. Moreover, with the increase in temperature, the nanoparticles become more active and produce large distance between the nanoparticles and this is due to weak adhesion forces in Nano fluid.

Batchelor proposed an expression for determining the dynamic viscosity for rigid and spherical particles [36]. In the model neglecting interactions between the particles, the expression is as follows:

$\mu_{n f}=\mu_{f}\left(1+2.5 \emptyset+6.2 \emptyset^{2}\right)$

where $\mu_{n f}$ is absolute viscosity of Nano fluid (m Pa.s), $\mu_{f}$ is absolute viscosity of base fluid (m Pa.s) and $\varnothing$ is weight concentration of nanoparticles (-).

Fig. 5 shows the measured viscosity of the Nano fluid at different concentrations at the room temperature $\left(25^{\circ} \mathrm{C}\right)$ compared to the Bachelor model. The results showed that the viscosity of all Nano fluids increased exponentially as a function of the concentration of nanoparticles. Given the relationship between the shear stress and shear rate, it indicates that the GNP Nano fluids behave as non-Newtonian fluids and that the shear stresses of Nano fluids are higher than that of base fluids of all concentrations so the concentration increased when shear stress increased. Another reason for the measured viscosity is higher because the accumulation of nanoparticles in the Nano fluid is higher than that in the ideal suspension (Bachelor model), and these results are similar to many previous studies [37 - 38].

\section{2- Density}

Density is an effective thermo physical property to be studied, as the effect of density is to increase the pumping power and the mass flowrate in the case of high density nanofluids. Density of water and graphene-based nanofluids were measured using a Portable digital density meter (DMA 35, Anton Paar CO., and USA) [39] that shown in Fig 6. The results illustrated in Fig. 7 show that the nanofluid density increased when the concentration of nanoparticle was increased. The density decreases as the temperature raises. The values of the nanofluids densities which increased with increasing nano material concentration are shown in Fig. 8.

The equation used to calculate the nanofluid density introduced by Pak and Cho [38] as follows:

$\rho_{n f}=(1-\emptyset) \rho_{f}+\emptyset \rho_{p}$ 
where $\rho_{n f}$ is density of nanofluid $\left(\mathrm{kg} / \mathrm{m}^{3}\right), \rho_{f}$ is the density of base fluid $\left(\mathrm{kg} / \mathrm{m}^{3}\right)$ and $\emptyset$ is weight concentration of nanoparticles $(-)$.

\subsection{Thermal conductivity}

Thermal conductivity is playing vital role for improving the convective heat transfer coefficient. In this study the thermal conductivity of nanofluid was calculated with equations (3-5) were considered precise equations for calculating the thermal conductivity of solid and liquid mixtures containing spherical particles. The results in Fig.9 indicate increase in thermal conductivity upon increasing particle concentration. The thermal conductivity increases with Brownian motion, which occurs as interaction between nanoparticles and molecules of basic fluids and causes smaller nanoparticles to raise their surfaces and increase the number of interactions between them, which lead to increase in thermal conductivity.

$\frac{k_{n f}}{k_{f}}=\frac{k_{p}+2 k_{f}-2 \emptyset\left(k_{f}-k_{p}\right)}{k_{p}+2 k_{f}+\emptyset\left(k_{f}-k_{p}\right)}($ Maxwell $)$

$k_{n f}=k_{f}\left(4.97 \emptyset^{2}+2.72 \emptyset+1\right) \quad$ (Hamilton $)$

$k_{n f}=k_{f}\left(1+3 \emptyset+4.51 \emptyset^{2}\right) \quad($ Lu and Lin $)$

where $k_{n f}, k_{f}$ and $k_{p}$ are thermal conductivity of nanofluid, base fluid and nanoparticle respectively (W/m.K) and they are dimensionless and $\emptyset$ is weight concentration of nanoparticles $(-)$.

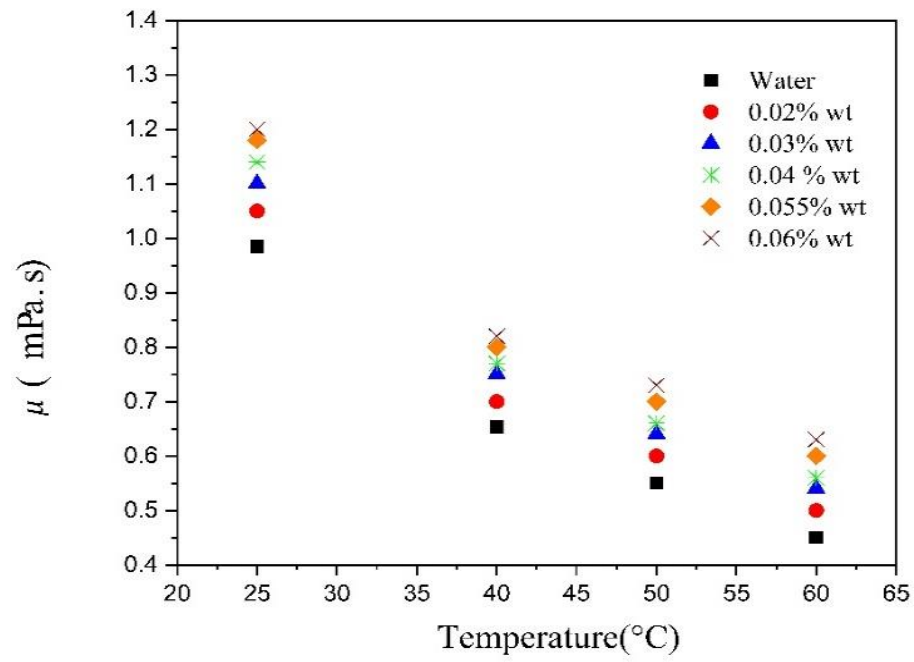

Fig. 4 The GNP nanofluids viscosity at different temperatures.

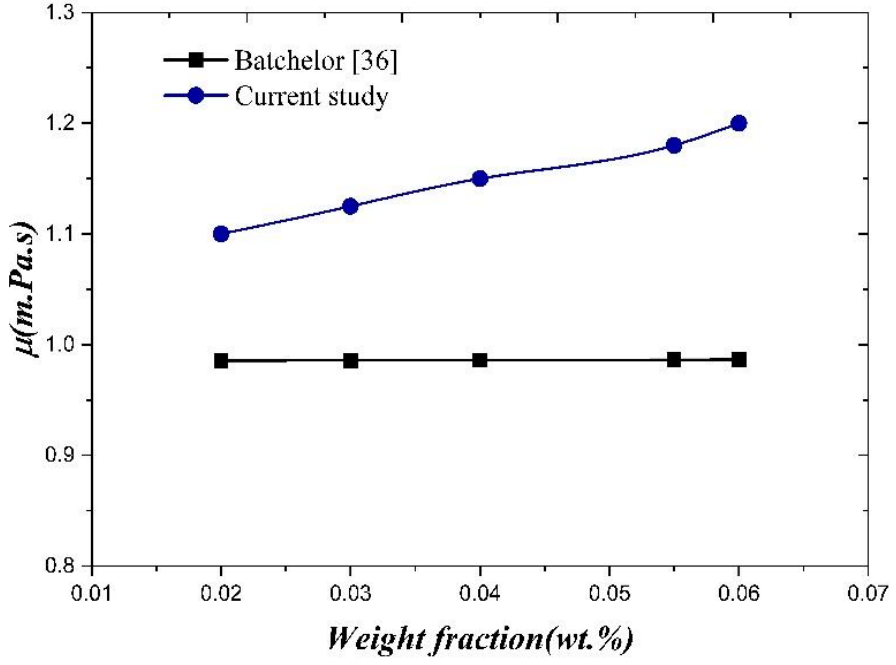

Fig. 5 Comparison between the viscosity of Nano fluid GNP in the current study and the theoretical model at $25^{\circ} \mathrm{C}$

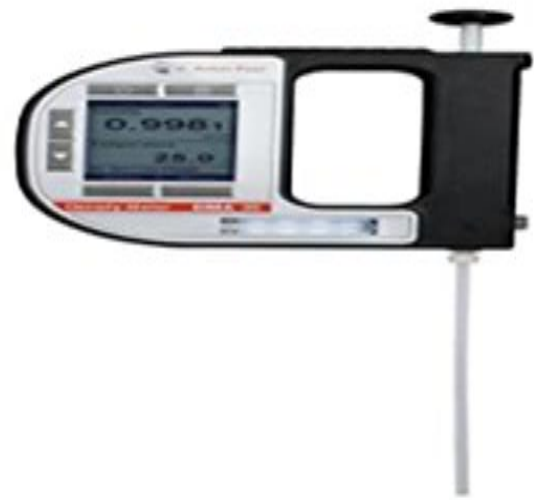

Fig. 6 Portable digital density meter [39].

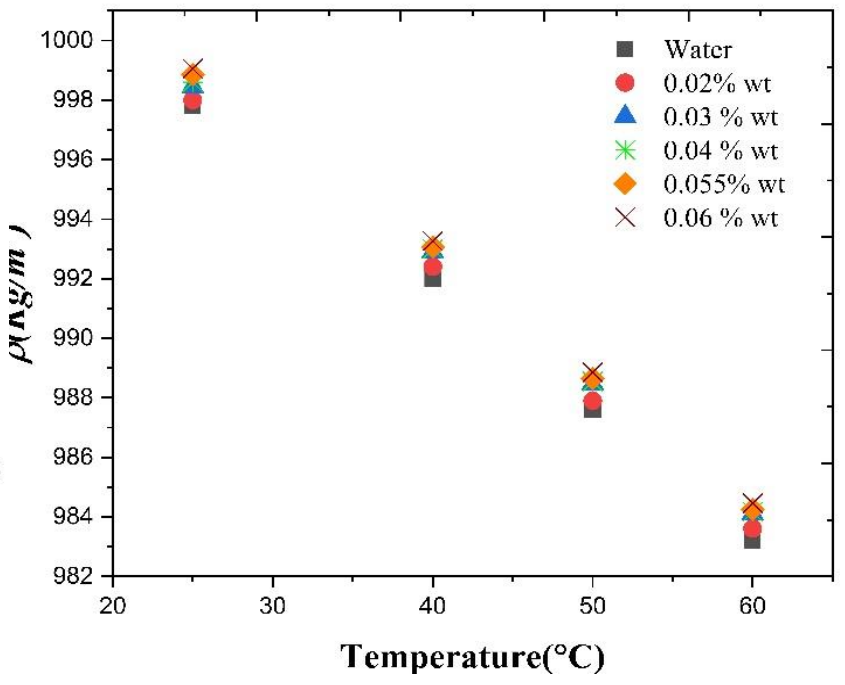

Fig.7 Density of the GNP Nano fluids at different temperatures. 


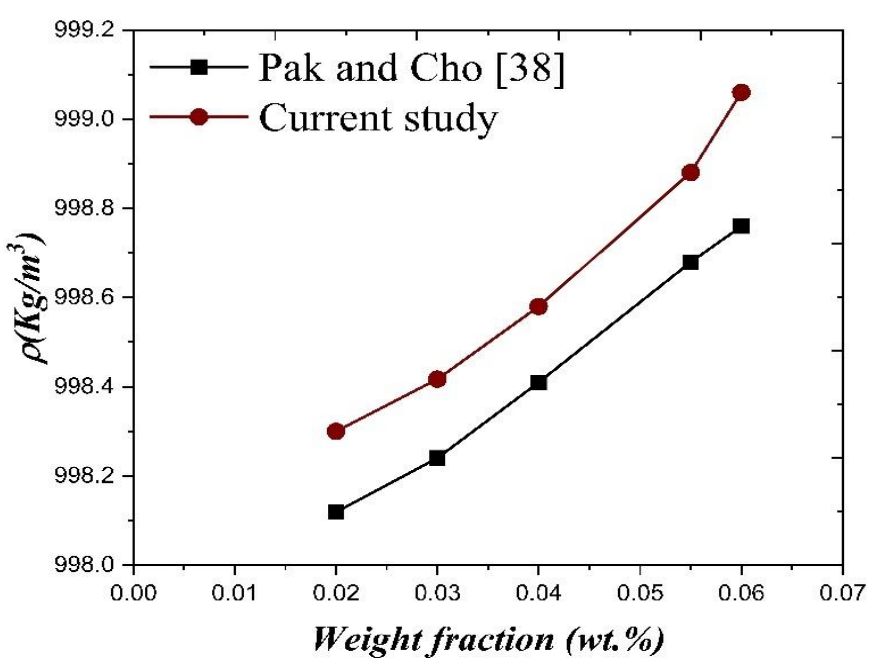

Fig. 8 Comparison between density of Nano fluid GNP in the current study and the theoretical model at $25^{\circ} \mathrm{C}$.

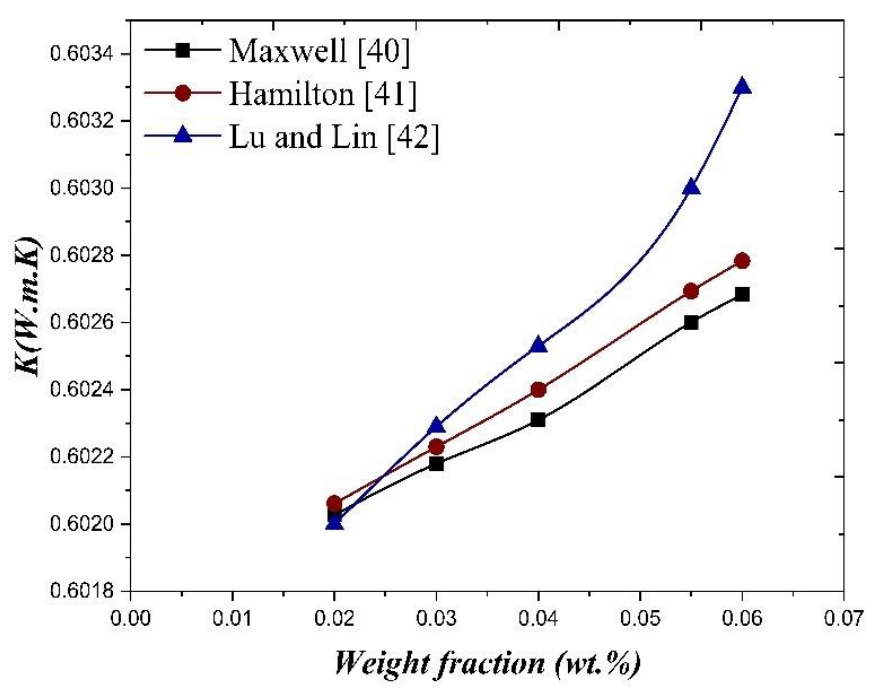

Fig. 9 Thermal conductivity of graphene Nano fluid.

\section{4- Experimental setup}

For the current study, the experimental setup is shown in Fig. 10 and Fig. 11. The DMHE consists of two stainless steel conductors and tubes (Swagelok; Japan). The dimensions of the tubes are listed in Table 2. Thermocouples (K-type) are fixed at the inlet and outlet hot and cold flow which connected by the data logger (GL100 Data Logger GRAPHTEC Co. Japan) [43] for data logging. Via the inner tube, digital pressure sensor (APV80 Series KEYENCE, USA) [44] is used to measure the pressure drop. Rubber insulation is used to reduce the heat loss. The small gear pump (WT3000-1JB, Longer Precision Pump Co., Ltd) [45] continuously pushes the hot liquid into the inner tube at different flow rates with different pumping heads continuously. In this experimental study, the laminar flow of the Nano fluid through the inner tube is called the hot liquid. The cooling water passed as a backflow into DMHE and used as a cold liquid.

Table 2. Dimensions of Double Micro Heat Exchanger (DMHE) piping

\begin{tabular}{|c|c|c|}
\hline Types of tubes & Inner tube & Outer tube \\
\hline Inner diameter & 0.02 in $(0.51 \mathrm{~mm})$ & 0.1 in $(2.58 \mathrm{~mm})$ \\
\hline Outer diameter & $0.063 \mathrm{in}(1.5875 \mathrm{~mm})$ & $0.125 \mathrm{in}(3.175 \mathrm{~mm})$ \\
\hline Length & $6.89 \mathrm{in}(170 \mathrm{~mm})$ & $6.89 \mathrm{in}(170 \mathrm{~mm})$ \\
\hline
\end{tabular}

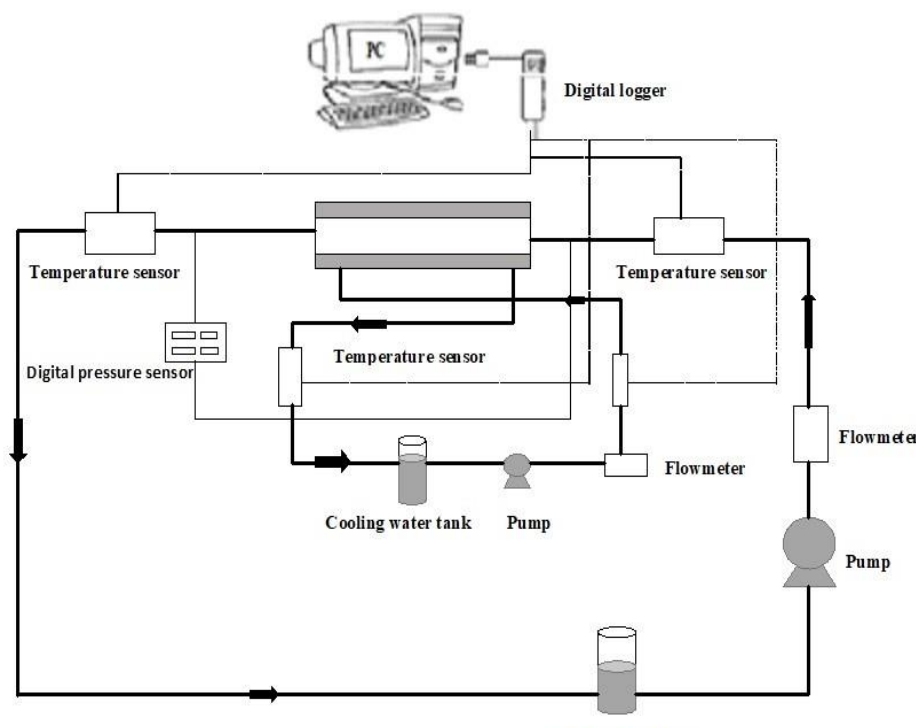

Hot nan ofluid tank

Fig.10 Schematic diagram of DMHE

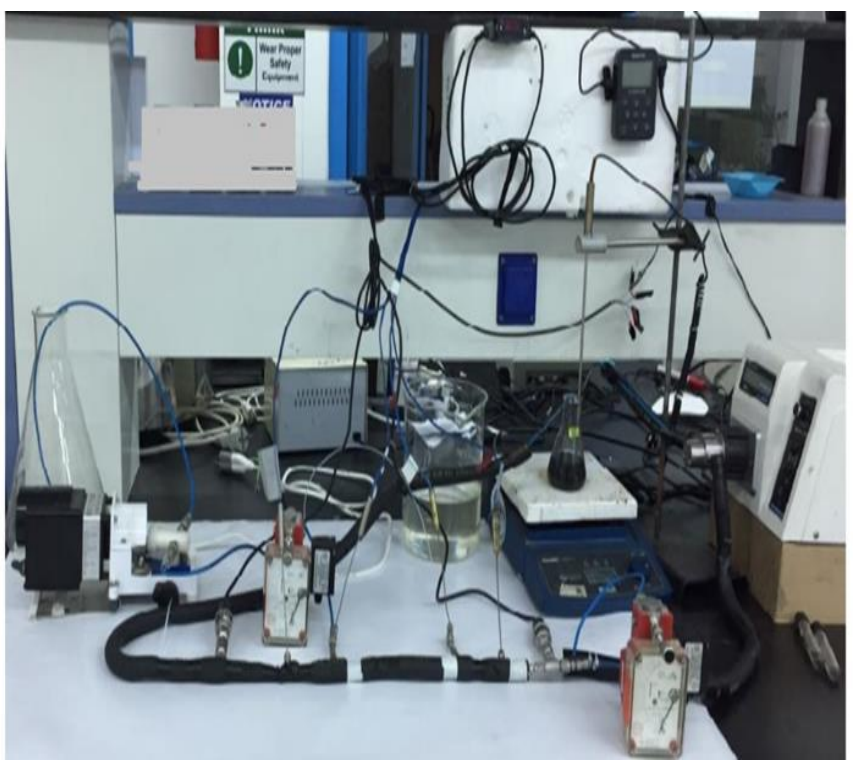

Fig.11 Photograph of the experimental set-up. 


\subsection{Data Processing}

The performance of heat exchanger can be assessed by many variants; the overall heat transfer coefficient is one of them. This variant describes the more heat transfer between two fluids. The overall heat transfer coefficient and the variations of Logarithmic mean temperature difference (LMTD) for graphene nanofluid in laminar flow at different Reynolds numbers are calculated using equations from (6-15) [46] as follows:

$$
Q_{n f}=\dot{m}_{n f}\left(h_{n f, i}-h_{n f, o}\right)=\dot{m}_{n f} C p_{n f}\left(T_{n f, i}-T_{n f, o}\right)
$$

Where $Q, \dot{m}$ and $h$ are heat transfer rate $(\mathrm{J} / \mathrm{s})$, mass flowrate $(\mathrm{kg} / \mathrm{s})$ and convective heat transfer $\left(\mathrm{W} / \mathrm{m}^{2} \mathrm{~K}\right)$; respectively

$$
Q_{\text {avg }}=\frac{Q_{h}+Q_{C}}{2}
$$

where $Q_{a v g}$ is the average heat transfer rate $(\mathrm{J} / \mathrm{s})$

$$
\frac{\text { Qavg }}{\text { A*LMTD }}
$$

where $U, A$ and $L M T D$ are the overall heat transfer coefficient $\left(\mathrm{W} / \mathrm{m}^{2} \mathrm{~K}\right)$, heat transfer area $\left(\mathrm{m}^{2}\right)$ and Logarithmic Mean Temperature Difference $(\mathrm{K})$ respectively

$$
\begin{aligned}
& A=\pi D L \\
& L M T D=\frac{\left(T_{n f, i}-T_{c, o}\right)-\left(T_{n f, o}-T_{c, i}\right)}{\operatorname{Ln}\left[\frac{\left(T_{n f, i}-T_{c, o}\right)}{\left(T_{n f, o}-T_{c, i}\right)}\right]} \\
& h_{n f}=\frac{Q_{h}}{L M T D A_{h}} \\
& N u=\frac{h_{n f} * D_{i}}{k_{n f}}
\end{aligned}
$$

where $D_{i}$ is the inner diameter of inner tube (m).

$$
C=\frac{(\dot{m} * c p)_{h}}{(\dot{m} * c p)_{c}}
$$

where, $C$ is the thermal capacity ratio (-).

$$
N T U=\frac{U * A}{(\dot{m} * c p)_{h}}
$$

$N T U$ is the number of transfer units (-).

$$
\varepsilon=\frac{1-\exp [-N T U(1-C)]}{1-C * \exp [-N T U(1-C)]}
$$

\section{5-RESULTS AND DISCUSSION: \\ 5.1 Convective heat transfer of Nano fluid}

The overall heat transfer $(U)$ and $L M T D$ for water and graphene Nano fluid at different Reynolds number; $R e$ values in laminar flow are explained in Fig. 12 and Fig. 13 respectively.

In Fig. 12, it may be noticed that $L M T D$ values reduced by adding GNPs to water, according to Eq. 6 an inverse ratio between $U$ and $L M T D$, when the overall heat transfers coefficient reduces, the $L M T D$ increase. In Fig. 13, the results state that overall heat transfers coefficient increased with increasing the Nano fluid concentration compared to the base fluid at $R e=425$, the overall heat transfers coefficient increased by $51.1 \%, 47.3 \%$ and $37 \%$ for $0.06 \%$ wt, $0.055 \%$ wt. and $0.02 \%$ wt. respectively. In these experiments, the nanomaterial concentration is the most efficient variant responsible for increasing the overall heat transfer coefficient. The enhancements of convective heat transfer of Nano fluid result from the suspended particles which increase the thermal conductivity of the mixture and the chaotic movement of the nanoparticles accelerates energy exchange process in the fluid.

Fig.14. illustrate the convective heat transfer improvements at different Reynolds numbers in the laminar regime of water and Nano fluids resulting from the addition of nanoparticles to water. The results indicate that the increase in the heat transfer coefficients compared to the base fluid were $22 \%, 15.56 \%$, and $13.33 \%$ for $0.06 \%$ wt., $0.055 \%$ wt. and $0.02 \%$ wt. respectively for GNP Nano fluid at $R e=425$.

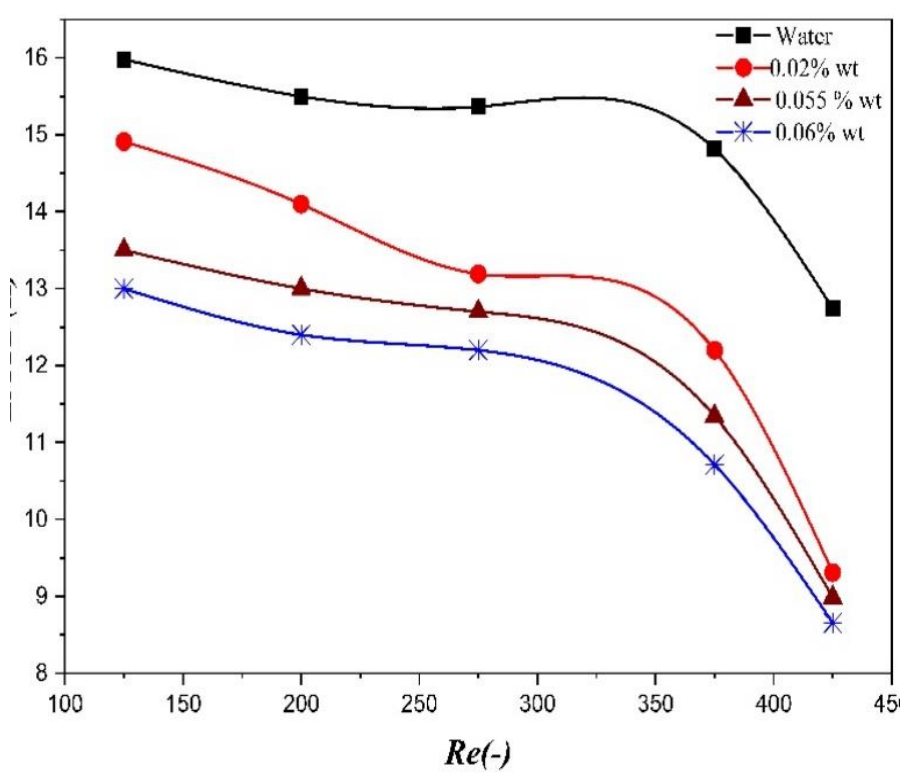

Fig. 12 LMTD of GNPs Nano fluids and water variation on different Reynolds numbers. 


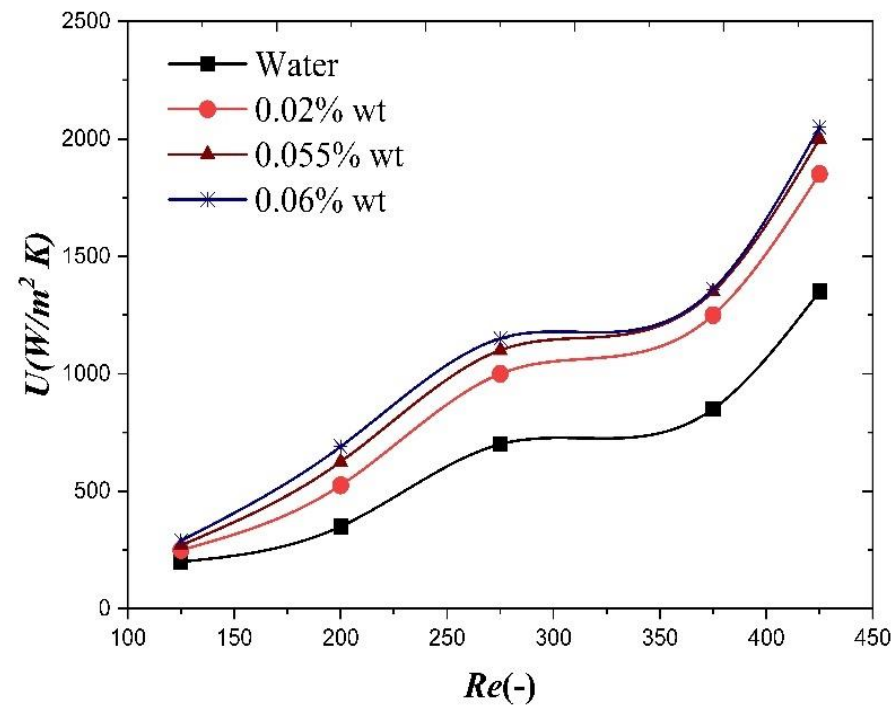

Fig.13 Overall heat transfer coefficient (U) of graphene Nano fluids and water variation on different Reynolds numbers.

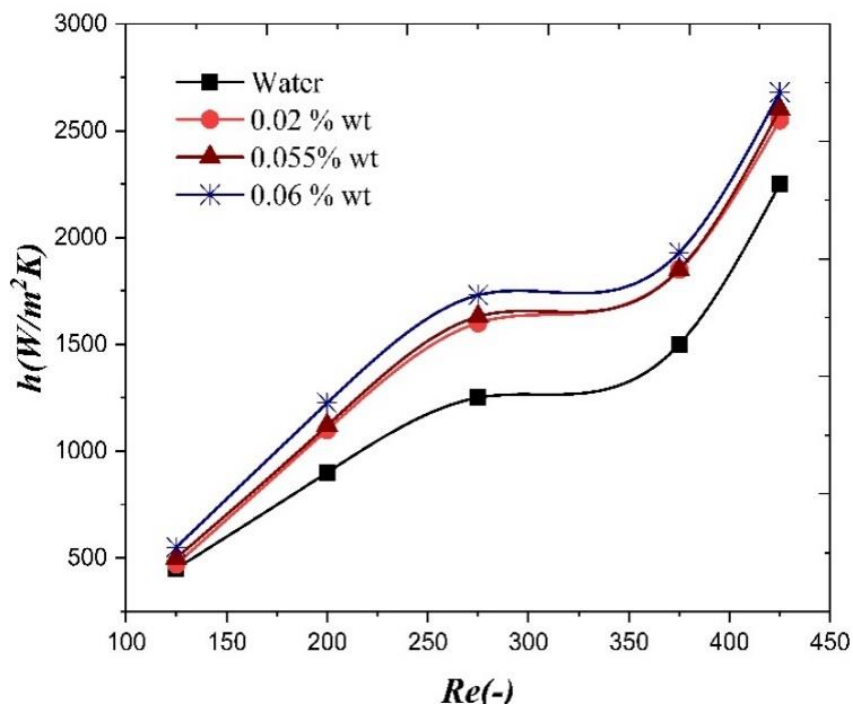

Fig. 14 Convective heat transfer coefficient for laminar flow of water and graphene Nano fluids

\subsection{Heat exchanger effectiveness at different Reynolds number}

The heat exchanger effectiveness is used to study the performance of heat transfer for the heat exchanger. In Fig. 15, the results show that the effectiveness of heat exchanger while incorporating Nano fluid increased significantly with the increase of GNPs concentration. It is detected that as the Reynolds number increases, the effectiveness increases. In addition, it may be observed that the effectiveness of heat exchanger incorporating Nano fluids is higher that of utilizing distilled water. The thermal effectiveness increased at $R e=375$ by $19 \%, 21 \%$ and $25 \%$ for $0.02 \%$ wt., $0.055 \%$ wt. and 0.06 wt $\%$ respectively compared to distilled water.

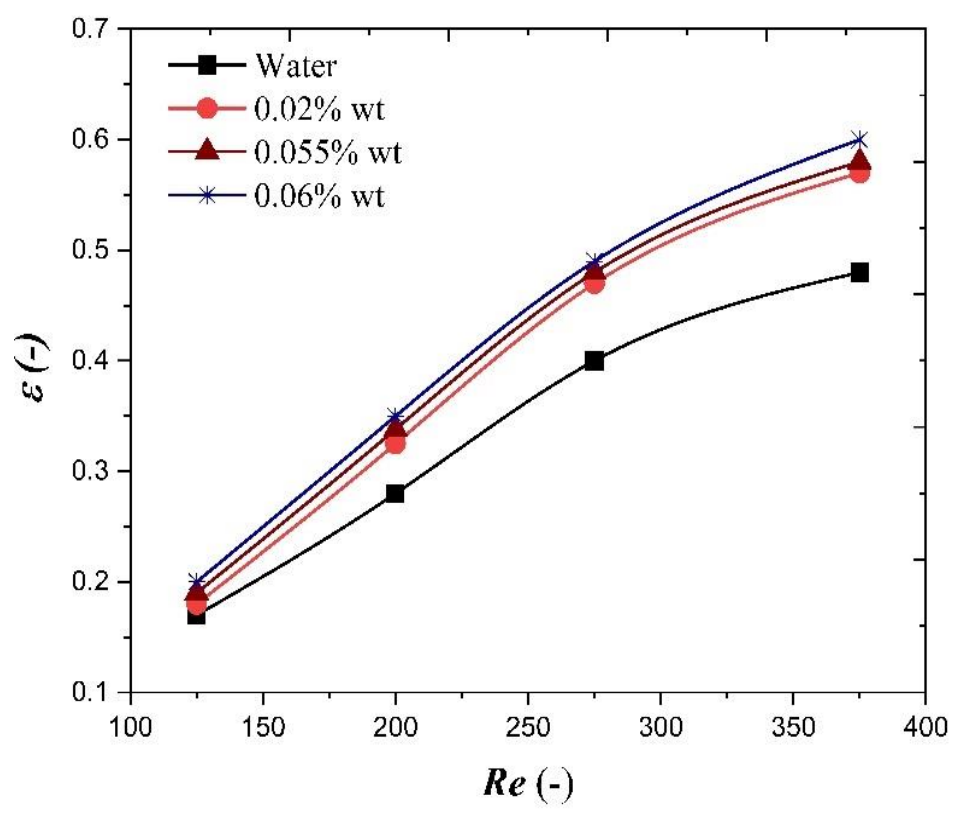

Fig.15 Heat exchanger effectiveness as a function of Reynolds number for different Nano fluids and base fluid.

5.3 Pressure drop and pumping power across micro tube using graphene nanofluid:

The experimental friction factor values have been determined from the measured pressure drop; $(\Delta P),(\mathrm{Pa})$ at laminar flow from equations (16-19) [47] as follows:

$$
f=\frac{2 * \Delta p}{\rho v^{2}\left(\frac{L}{d}\right)}
$$

where, $f$ is the friction factor $(-), \Delta P$ is the pressure drop $(\mathrm{Pa})$, $\rho$ is the density of working fluid $\left(\mathrm{kg} / \mathrm{m}^{3}\right), v$ is the flow velocity $(\mathrm{m} / \mathrm{s}), L$ is the length of pipe $(\mathrm{m})$ and $d$ is the inner diameter of the pipe(m).

While the theoretical friction factor $f_{t h}$ was determined by Darcy's equation:

$$
\mathrm{f}_{t h}=\frac{64}{R e}
$$

To calculate the pumping power; $P(\mathrm{~W})$, required to flow the base fluid in tubes, it was calculated according to the following equation while $\varphi$ is volumetric flow rate $(l / \mathrm{s})$ :

$$
\begin{aligned}
& P=\Delta p * \varphi \\
& \varphi=A v
\end{aligned}
$$

The measured pressure drops $;(\Delta P)$, were used to calculate the friction factors of the Nano fluid in the laminar flow microtube using Eq.(15).The theoretical friction factor was calculated 
according to Eq. (16). Fig.16 illustrates comparison between the actual and theoretical values of friction factor versus the Reynolds number for water. The results shows that the theoretical and actual values of friction factor are nearly close to each other.

Fig. 17 shows the variation of the friction factor of graphene Nano fluids with Reynolds number. The results illustrate that the Nano fluid with the higher concentration of $0.06 \mathrm{wt} . \%$ has the highest friction factor. The increase in friction factor compared to the base fluid for $0.06 \%$ wt is $45.65 \%$ at $R e=100$. The reason for increasing the friction factor may be attributed to an increase in the weight fraction, lead to an increase in the viscosity of the fluid which reduces and resists the fluid flow.

As shown in Fig. 18, the pumping power; $(P)$, enlarges with the weight fraction of GNPs in the Nano fluid for all Reynolds numbers. The results indicate that the pumping power increase by $50 \%, 40 \%$ and $25 \%$ for $0.06 \%$ wt., $0.055 \%$ wt. and $0.02 \%$ wt. respectively compared to distilled water at $R e=400$. This means that the Nano fluids increase the pumping power due to the increase in nanoparticle concentration and also the increase the GNPs friction factor lead to an increase in pumping power.

Fig. 19 shows the effect of weight fraction of graphene Nano fluid on pressure drop versus volume flow rate. The results show that the pressure drop increases with increasing the Nano fluid concentrations. The results showed that the pressure drop of $0.06 \%$ wt. compared to distilled water was $17.87 \%$ higher at volumetric flow rate $=0.09 \mathrm{l} / \mathrm{s}$ and it is considered the highest pressure drop. The variations in pressure drop may be attributed to many causes, one of which is the concentration of the Nano fluid that affects the thermos-physical properties and these causes lead to change in the values of the pressure drop.

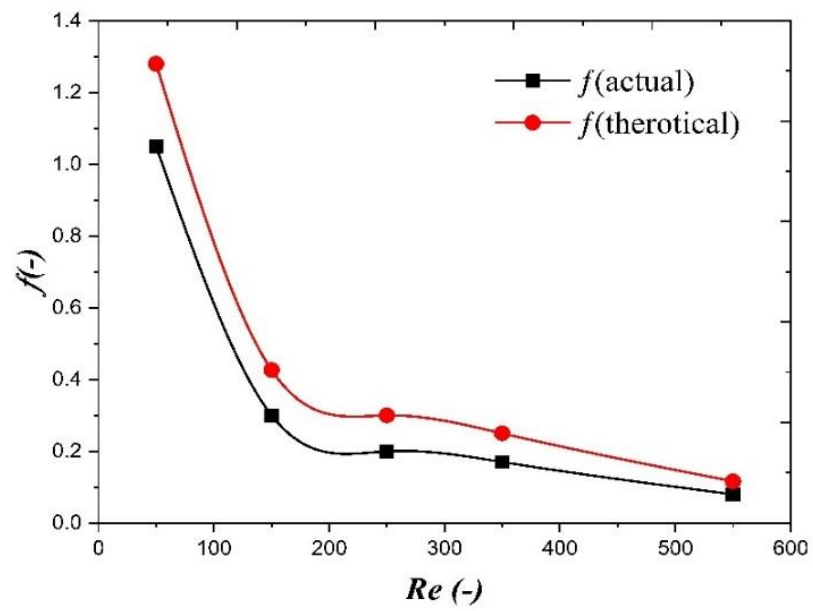

Fig.16 Comparison between measured and theoretical value of water friction factors.

Fig. 20 shows the variation of heat transfer rate / pumping power ratio $(Q / P)$ with Reynolds number at different weight concentrations. The results indicate that the $Q / P$ value decreases with the increase of concentration of Nano fluid, and increase with the increase of Reynolds number to achieve the peak value and then decreases. This may be attributed to that $Q$ and $\mathrm{P}$ increase with the increase of Reynolds number. However, the rate of increase of $Q$ till the peak value is higher than the rate of increase of $P$ and that the rate of increase of $Q$ is lower than that of increase of $P$ for values of Reynolds numbers higher than that corresponding to the peak value of $Q / P$ ratio.

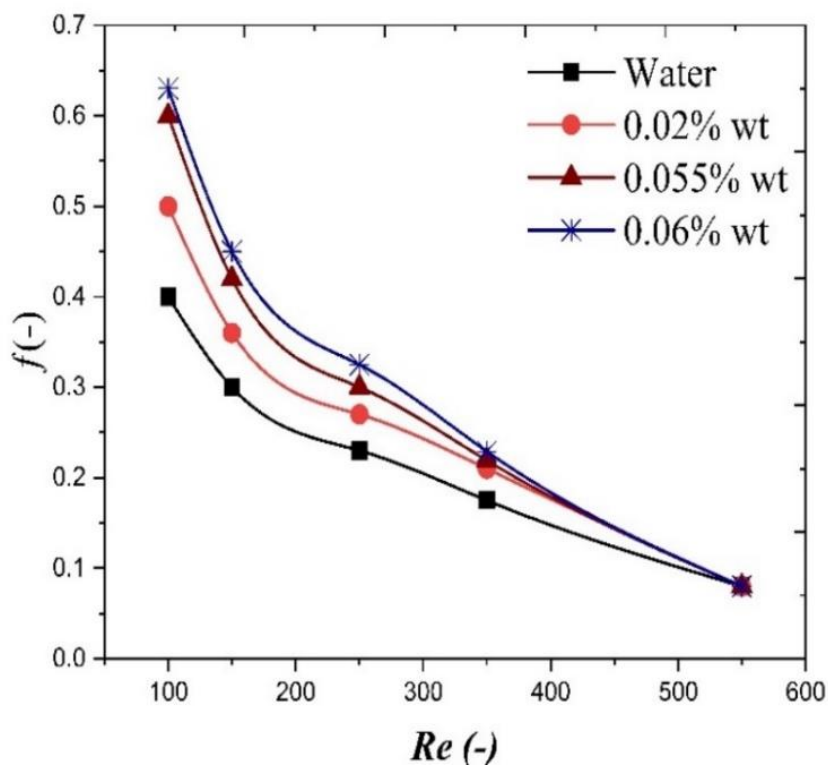

Fig.17 Nano fluid friction factor at different Reynolds number.

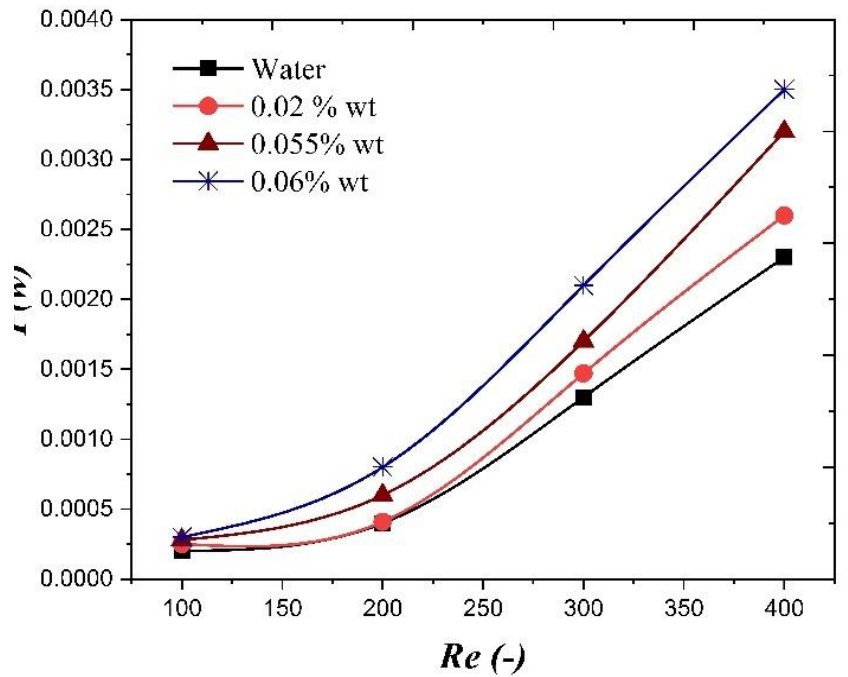

Fig. 18 Pumping power of Nano fluid GNPs concentrations versus Reynolds number. 


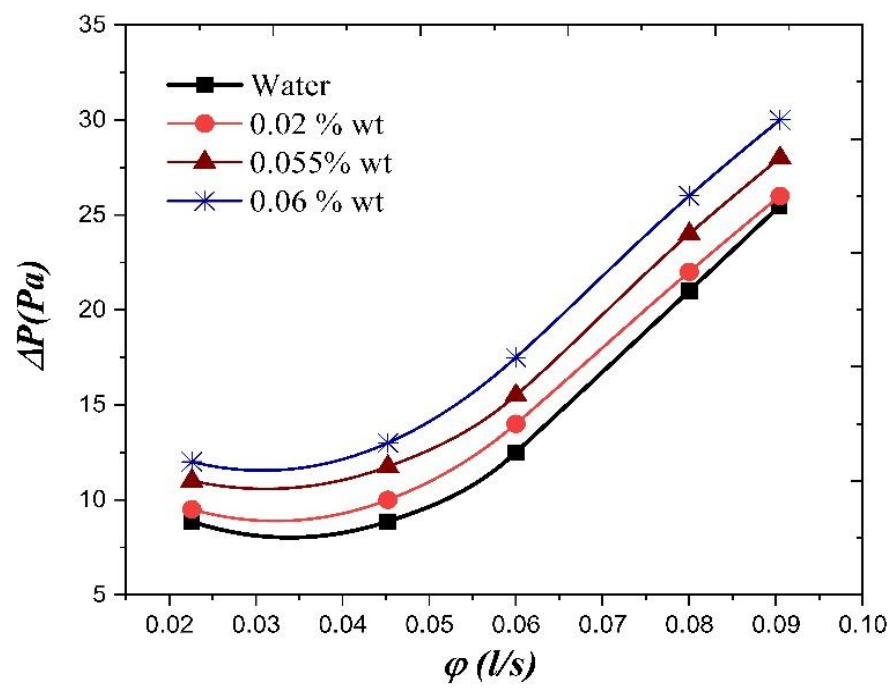

Fig. 19 Effect of Weight fractions of GNPs at pressure drop versus volume flow rate.

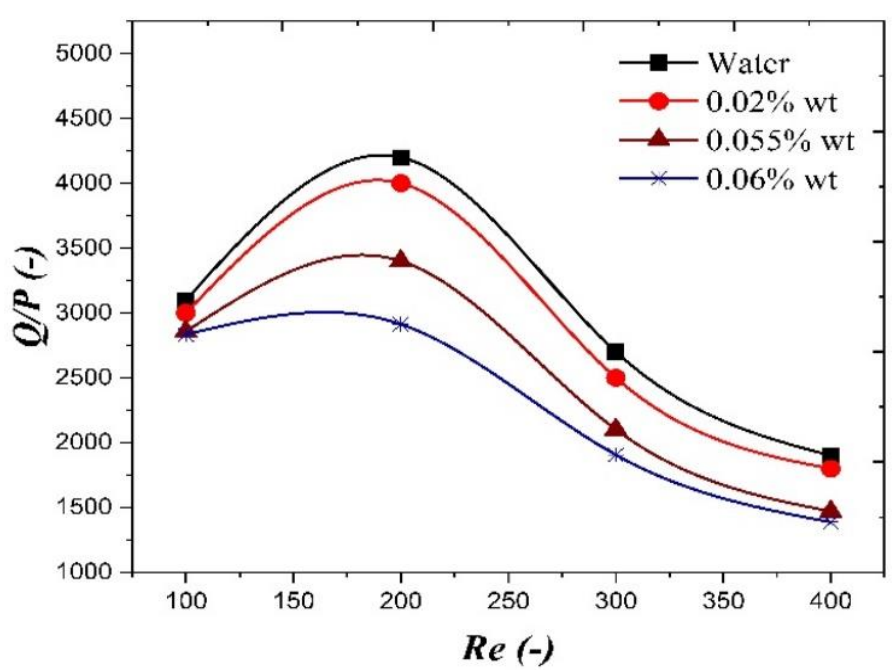

Fig. 20 Ratio of $(Q / P)$ of Nano fluid GNPs concentrations versus Reynolds number.

\section{6- CONCLUSION}

In the experimental study, laminar flow in DMHE with various concentrations of Graphene Nano fluid (0.02, 0.055and $0.06 \%$ wt.) which was prepared using two steps technique and the thermo physical properties were measured. In this study, it was found that the weight fraction of GNPs had a remarkable effect on the heat transfer coefficient, thermal effectiveness, pressure drop and pumping power. The experimental results can be concluded as follows:

1-The temperature has remarkable effect on density and viscosity of graphene Nano fluid, when the density and viscosity were increased with increasing temperature.

2-The thermal conductivity was enhanced for graphene Nano fluid and the results indicate increase in the thermal conductivity by increasing the concentration of the Nano fluid.

3-Enhancement of the convective heat transfer coefficient of graphene Nano fluid at various concentrations $(0.02,0.055$ and
$0.06 \%$ wt.) was compared with distilled water and the results showed that the highest enhancement was achieved in the $0.06 \%$ wt. concentration.

4-The thermal effectiveness of Nano fluids (0.02, 0.055and $0.06 \%$ wt.) was higher than distilled water

5-Finally, the results showed that the friction factor of 0.02 , 0.055 and $0.06 \%$ wt. are higher than friction factor of distilled water and the pumping power and pressure drop of Nano fluid were higher than that of water.

\section{References}

[1] M. Mehrali, E. Sadeghinezhad, S.T. Latibari, S.N. Kazi, M. Mehrali, M.N.B.M. Zubir and H.S.C. Metselaar, "Investigation of thermal conductivity and rheological properties of Nano fluids containing graphene Nano platelets", Nanoscale Res. Lett. 9 (1) (2014) 1-12

[2] M. Mehrali, S. Tahan Latibari, M. Mehrali, T.M.I. Mahlia, E. Sadeghinezhad and H.S.C. Metselaar, "Preparation of nitrogen-doped graphene/palmitic acid shape stabilized composite phase change material with remarkable thermal properties for thermal energy storage", Appl. Energy 135 (2014) 339-349

[3] S.U.S. Choi, J. Eastman, "Enhancing thermal conductivity of fluids with nanoparticles", Argonne National Lab., IL, United States, 1995, pp. 99-105.

[4] M. R. Safaei, H. Togun, K. Vafai, S. N. Kazi, and A. Badarudin,

"Investigation of heat transfer enhancement in a forward-facing contracting channel using FMWCNT nanofluids," Number. Heat Transf. Part A Appl., vol. 66, no. 12, pp. 1321-1340, 2014, doi: 10.1080/10407782.2014.916101.

[5] M. Mehrali, S.T. Latibari, M. Mehrali and T.M. Indra Mahlia, H.S. Cornelis Metselaar, M.S. Naghavi, et al., "Preparation and characterization of palmitic acid/graphene Nano platelets composite with remarkable thermal conductivity as a novel shape-stabilized phase change material", Appl Therm Eng 61 (2013) 633-640.

[6] M. Hassan, R. Sadri, G. Ahmadi and M. B. Dahari, "Numerical study of entropy generation in a flowing nanofluid used in micro- and mini channels,' Entropy, vol. 15, no. 1, pp. 144-155, 2013, doi: 10.3390/e15010144.

[7] M. Mehrali, S.T. Latibari, M. Mehrali, T.M. Indra Mahlia and H.S. Cornelis Metselaar, "Preparation and properties of highly conductive palmitic acid/graphene oxide composites as thermal energy storage materials," Energy 58 (2013) 628-634

[8] H. Yarmand, S. Gharehkhani, S.N. Kazi, E. Sadeghinezhad and M.R. Safaei, "Numerical investigation of heat transfer enhancement in a rectangular heated pipe for turbulent Nano fluid," Sci. World J. 2014 (2014) 9.

[9] M. Shanbedi, S.Z. Heris, M. Baniadam, A. Amiri and M. Maghrebi, "Investigation of heat-transfer characterization of EDA-MWCNT/DI-water Nano fluid in a two-phase closed thermosiphon," Ind. Eng. Chem. Res. 51 (3) (2012) 1423-1428.

[10] M. Memari, A. Golmakani and A.M. Dehkordi, "Mixed-convection flow of nanofluids and regular fluids in vertical porous media with viscous heating," Ind. Eng. Chem. Res. 50 (15) (2011) 9403-9414.

[11] W. Azmi, K. Sharma, P. Sarma, R. Mamat and S. Anuar, "Comparison of convective heat transfer coefficient and friction factor of $\mathrm{TiO}_{2}$ nanofluid flow in a tube with twisted tape inserts," Int. J. Therm. Sci. 81 (2014) 84-93.

[12] H. Togun, M.R. Safaei, R. Sadri, S.N. Kazi, A. Badarudin, K. Hooman and E. Sadeghinezhad, "Numerical simulation of laminar to turbulent Nano fluid flow and heat transfer over a backward-facing step," Appl. Math. Comput. 239 (2014) 153-170.

[13] E. Sadeghinezhad, M. Mehrali, S. Tahan Latibari, M. Mehrali, S.N. Kazi, S. Oon and H.S.C. Metselaar, "Experimental investigation of convective heat transfer using graphene Nano platelet-based Nano fluids under turbulent flow conditions," Ind. Eng. Chem. Res. 53 (31) (2014) 12455-12465.

[14] K. J. Wu, C. X. Zhao, G. H. Xu, and C. H. He, "Investigation of convective heat transfer with liquids in microtubes,” Ind. Eng. Chem. Res., vol. 51, no. 27, pp. 9386-9395, 2012, doi: 10.1021/ie301174j.

[15] R. Azizian, E. Doroodchi, T. McKrell, J. Buongiorno, L. Hu and B. Moghtaderi, "Effect of magnetic field on laminar convective heat transfer of magnetite Nano fluids," Int. J. Heat Mass Transfer 68 (2014) 94-109.

[16] R. Sadri, G. Ahmadi, H. Togun, M. Dahari, S.N. Kazi, E. Sadeghinezhad and N. Zubir, "an experimental study on thermal conductivity and viscosity of Nano fluids containing carbon nanotubes," Nanoscale Res. Lett. 9 (1) (2014) 151 
[17] W. Duangthongsuk and S. Wongwises, "An experimental study on the heat transfer performance and pressure drop of $\mathrm{TiO}_{2}$-water nanofluids flowing under a turbulent flow regime", Int. J. Heat Mass Trans. 53(2010) 334-344.

[18] E. F. Akyürek, K. Geliş, B. Şahin, and E. Manay, "Experimental analysis for heat transfer of nanofluid with wire coil turbulators in a concentric tube heat exchanger," Results Phys., vol. 9, pp. 376-389, 2018, doi: 10.1016/j.rinp.2018.02.067.

[19] K. J. Lee, S. H. Yoon, and J. Jang, "Carbon nanofibers: A novel nanofiller for nanofluid applications," Small, vol. 3, no. 7, pp. 1209-1213, 2007, doi: 10.1002/smll.200700066.

[20] H. Dongxiao, M. Zhaoguo, W. Daxiong, Z. Canying and Z. Haitao, "Thermal properties of carbon black aqueous Nano fluids for solar absorption Nanoscale" Res. Lett. 6 (2011) 457.

[21] A. Nasiri, M. Shariaty-Niasar, A.M. Rashidi and R. Khodafarin, "Effect of CNT structures on thermal conductivity and stability of Nano fluid," Int. J. Heat Mass Transfer 55 (5-6) (2012) 1529-1535

[22] S.W. Lee, K.M. Kim and I.C. Bang, "Study on flow boiling critical heat flux enhancement of graphene oxide/water Nano fluid," Int. J. Heat Mass Transfer 65 (2013) 348-356.

[23] W. Yu, H. Xie and X. Wang, X. Wang, "Significant thermal conductivity enhancement for Nano fluids containing graphene Nano sheets," Phys. Lett. A 375 (10) (2011) 1323-1328.

[24] R. Zheng, J. Gao, J. Wang, S.P. Feng, H. Ohtani, J. Wang, and G. Chen, "Thermal percolation in stable graphite suspensions," Nano Lett. 12 (1) (2011) $188-192$.

[25] K.S. Novoselov, A.K. Geim, S.V. Morozov, D. Jiang, Y. Zhang, and S.V. Dubonos. "Electric Field Effect in Atomically Thin Carbon Films." Science 2004; 306: 666-9.

[26] A. A. Balandin, S. Ghosh, W. Bao and I. Calizo, "Superior thermal conductivity of single-layer graphene," Nano Lett., vol. 8, no. 3, pp. 902-907, 2008, doi: 10.1021/n10731872.

[27] T. T. Baby and S. Ramaprabhu, "Enhanced convective heat transfer using graphene dispersed nanofluids," Nanoscale Res. Lett., vol. 6, no. 1, pp. 1-9, 2011, doi: 10.1186/1556-276X-6-289.

[28] E. Ebrahimnia-Bajestan, H. Niazmand, W. Duangthongsuk, and S.

Wongwises, "Numerical investigation of effective parameters in convective heat transfer of nanofluids flowing under a laminar flow regime," Int. J. Heat

Mass Transf., vol. 54, no. 19-20, pp. 4376-4388, 2011, doi:

10.1016/j.ijheatmasstransfer.2011.05.006.

[29] J.A. Eastman, U.S. Choi, S. Li, L.J. Thompson, and S. Lee, "Enhanced thermal conductivity through the development of nanofluids," Materials Research Society Symposium - Proceedings, vol. 457. pp. 3-11, 1997, [Online]. Available: https://www.osti.gov/servlets/purl/459378.

[30] S. U. S. Choi, S. Li, and J. A. Eastman, "Measuring thermal conductivity of fluids containing oxide nanoparticles," J. Heat Transfer, vol. 121, no. 2, pp. 280-289, 1999, doi: 10.1115/1.2825978.

[31] X. Wang, X. Xu, and S. U. S. Choi, "Thermal Conductivity of NanoparticleFluid Mixture," Journal of Thermophysics and Heat Transfer 13: 474-480, 1999.

[32] S. M. S. Murshed, K. C. Leong, and C. Yang, "Enhanced thermal conductivity of TiO2 - Water based nanofluids," Int. J. Therm. Sci., vol. 44, no. 4, pp. 367-373, 2005, doi: 10.1016/j.ijthermalsci.2004.12.005.

[33] K. Kwak and C. Kim, "Viscosity and thermal conductivity of copper oxide nanofluid dispersed in ethylene glycol," Korea Aust. Rheol. J., vol. 17, no. 2, pp. 35-40, 2005.

[34] J. P. Vallejo, E. Álvarez-Regueiro, D. Cabaleiro, J. Fernández-Seara, J Fernández, and L. Lugo, "Functionalized graphene nanoplatelet nanofluids based on a commercial industrial antifreeze for the thermal performance enhancement of wind turbines," Appl. Therm. Eng., vol. 152, pp. 113-125, 2019, doi: 10.1016/j.applthermaleng.2019.02.046.

[35] https://www.indiamart.com/proddetail/ostwald-u-tube-glass-viscometer22541702162.html

[37] G. K. Batchelor, "The effect of Brownian motion on the bulk stress in a suspension of spherical particles," J . Fluid Mech., vol. 83, no. 1, pp. 97-117, 1977.

$\left[3^{\vee}\right]$ E. V. Timofeeva, J. L. Routbort, and D. Singh, "Particle shape effects on thermophysical properties of alumina nanofluids," J. Appl. Phys., vol. 106, no. 1, 2009, doi: 10.1063/1.3155999.

[3^] Y. I. C. Bock Choon Pak, "Hydrodynamic and Heat Transfer Study of Dispersed Fluids with Submicron Metallic Oxide," Exp. Heat Transf. A J. , Therm. Energy Transp. , Storage , Convers., no. January 2013, pp. 37-41, 2013. [39]https://www.kwipped.com/rentals/product/anton-paar-portable-densitymeters-dma-35/13731

[ $• \cdot]$ J.C.A. Maxwell. Treatise on electricity and magnetism. Oxford, UK: Clarendon Press; 1881.

[๕)] R. L. Hamilton, "Thermal conductivity of heterogeneous two-component systems," Ind. Eng. Chem. Fundam., vol. 1, no. 3, pp. 187-191, 1962, doi: 10.1021/i160003a005.

$\left[\varepsilon_{Y}\right]$ S. W. Lee, S. D. Park, S. Kang, I. C. Bang, and J. H. Kim, "Effective conductivity of composites containing aligned spheroidal inclusions of finite conductivity," Int. J. Heat Mass Transf., vol. 54, no. 1-3, pp. 433-438, 2011, doi: 10.1016/j.ijheatmasstransfer.2010.09.026.

[43] https://www.instrumart.com/assets/Graphtec-GL100-Manual.pdf.

[44] https://www.keyence.com/products/process/pressure/ap-v80/models/.

[45] https://www.longerpump.com/index.php/GearPump/show/95.html .

[46] A. Bejan, "Heat transfer, second edition," 1995

[47] T. Camp and R. Figliola, "Fluid mechanics," Mechanobiol. Handb., pp. 23 44, 2011, doi: 10.2478/jtam-2013-0011. 